\title{
Different Surgical Techniques in Tubo-Ovarian Abscess Management
}

\author{
Hale GÖKSEVER ÇELIK' ${ }^{1}$, Engin ÇELİK², Semra YÜKSEL ${ }^{2}$ Ercan BAŞTU², \\ Hasan Cemal ARK ${ }^{1}$ \\ Istanbul,Turkey
}

\begin{abstract}
OBJECTIVE: Tubo-ovarian abscess is mostly a consequence of pelvic inflammatory disease. We aimed to compare success of the different surgical methods in tubo-ovarian abscess treatment.

STUDY DESIGN: 53 patients with tubo-ovarian abscess that were hospitalized and operated in the Department of Obstetrics and Gynecology at Kanuni Sultan Suleyman Training and Research Hospital during one year were included. Patients who had underwent salpingectomy/salpingo-oophorectomy and only abscess drainage were compared.
\end{abstract}

RESULTS: Salpingectomy/salpingo-oophorectomy had been done in $74.5 \%$ of cases and only drainage had been applied in $25.5 \%$ of cases. Difference in mean values between 2 groups were not observed except white blood cell count.

CONCLUSION: Treatment of tubo-ovarian abscess must be a combination of parenteral antibiotics and early surgical procedure to prevent poor outcomes. There is not any difference between different surgical techniques. But additionally more studies are needed to better understand which operation technique is more effective and less complicated.

Keywords: Tubo-ovarian abscess, Pelvic infections, Pelvic pain, Laparoscopy, Drainage

Gynecol Obstet Reprod Med 2017;23(1):32-36

\section{Introduction}

Tubo-ovarian abscess (TOA) is mostly a consequence of pelvic inflammatory disease (PID). However, endometritis, pyelonephritis, pelvic malignancy and any obstetric surgery may result in TOA. PID is caused by an ascending infection of lower genital tract organisms from the vagina or cervix into the uterus, fallopian tubes and peritoneal cavity (1). TOA

${ }^{1}$ Kanuni Sultan Süleyman Training and Research Hospital, Istanbul

${ }^{2}$ Istanbul University School of Medicine, Istanbul

${ }^{3}$ Taksim Gaziosmanpaşa Training and Research Hospital, Istanbul

Address of Correspondence: Hale Göksever Çelik

Astera Park Evleri A Blok Kat:11

Daire:47 Küçükçekmece Istanbul, Turkey

hgoksever@yahoo.com

Submitted for Publication: $\quad$ 14.10.2016

Accepted for Publication: $\quad$ 03.01.2017

\begin{tabular}{|c|c|}
\hline \multicolumn{2}{|c|}{ Access this article online } \\
\hline $\begin{array}{c}\text { Quick Response Code: } \\
\text { 口:sy: }\end{array}$ & website: www.gorm.com.tr \\
\hline 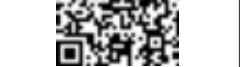 & DOI:10.201613/GORM.2016.639 \\
\hline
\end{tabular}

How to cite this article: Göksever Celik H. Celik E. Yüksel S. Baștu E. Ark HC. Different Surgical Techniques in Tubo-Ovarian Abscess Management. Gynecol Obstet Reprod Med 2017;23(1):32-36 is characterized by an inflammatory mass involving the fallopian tube, ovary and occasionally other adjacent pelvic organs (e.g. bladder, bowel) (2). Tubo-ovarian complex must be differentiated from TOA that has a true abscess wall (3). TOA can adhere to adjacent pelvic structures such as bowel, urinary bladder or omentum and this can result in elevated white blood cell count or fever. Polymicrobial infection with anaerobic bacteria predominantly cause TOA. The most commonly organisms that are isolated from TOA are Escherichia coli and Bacteroides species (4). Gonorrhea and Chlamydia may have a role to facilitate infection, but rarely isolated from an abscess (5).

The risk factors for TOA are multiple sexual partners, age between 15 to 45 years and a prior history of PID. Modern intrauterine devices (IUD) cause little increased risk for PID and TOA (6).

Lower abdominal or pelvic pain and adnexal mass are most commonly encountered symptoms in patients with TOA. Fever and leukocytosis may be absent (7). So absence of fever or elevated white blood cell count does not preclude the diagnosis of TOA. Vaginal discharge, nausea and abnormal vaginal bleeding may be present. Ruptured TOA may present with acute abdomen and signs of septic shock (8). Elevated C-reactive protein (CRP) and especially erythrocyte sedimentation rate $(\mathrm{ESR})(>50 \mathrm{~mm} / \mathrm{h})$ are good predictors for TOA $(9,10)$. 
Also these blood parameters are helpful for follow-up of treatment success.

Tubo-ovarian abscess is a serious life-threatening condition that must be diagnosed and managed immediately. While mortality associated with TOA is dramatically decreased over recent years prior to the advent of broad-spectrum antibiotics and modern surgical methods, morbidity associated with TOA remains significant. Because this can cause complications including infertility, ovarian vein thrombosis, chronic pelvic pain, pelvic thrombophlebitis and ectopic pregnancy (3).

Ruptured ovarian cysts, ovarian torsion, degenerated uterine fibroid, ectopic pregnancy or gastrointestinal pathologies such as appendicitis, gastroenteritis, irritable bowel syndrome or urinary tract pathologies (e.g. pyelonephritis, nephrolithiasis) have similar symptoms and signs. Complete history and pelvic examination and then further tests include the most important part of the diagnosis. Imaging studies such as ultrasonography, computed tomography (CT) or magnetic resonance imaging (MRI) are helpful for differential diagnosis of TOA. Transvaginal ultrasound is important because it is inexpensive, expose no radiation to the patient and show an excellent image about lower genital tract. TOA are characterized by a complex multilocular cystic mass with thick irregular walls and internal echoes (11).

Laparoscopy or laparotomy is necessary for both definitive diagnosis and treatment of TOA especially suspicious abscess rupture or finding of a TOA in a postmenopausal woman. Surgical exploration with removal of the involved tube and ovary and drainage of purulent fluid accumulated in pelvis is lifesaving (8). Treatment modalities include broad spectrum antibiotics, minimally-invasive drainage procedures, invasive surgery or combination of these modalities. The choice of treatment modality depends on the status of the patient and the characteristics of the abscess. In women treated surgically, antibiotics should also be started as soon as possible. In an unstable patient, surgery should not be delayed for administration of antibiotics.

Our objective was to define the characteristics of patients who undergo surgical treatment with the indication of TOA. We also aimed to compare characteristics of the patients according to different surgical techniques.

\section{Material and Method}

53 patients with TOA that were hospitalized and operated in the Department of Obstetrics and Gynecology at Kanuni Sultan Suleyman Training and Research Hospital between April 2014 and April 2015 were included. Most of the patients with TOA undergo operation in our clinics. So patients who had been observed only and not been hospitalized were excluded from our study.

Tubo-ovarian abscess had been diagnosed mainly by transvaginal ultrasonography or any other imaging techniques like CT or MRI. Age, gravidity and parity, cesarean history, number of normal vaginal delivery, presence of intrauterine device (IUD), any chronic disease, operation history, size of the TOA, CA125 and CRP level, white blood cell (WBC) count, incision type, operation technique, postoperative complication, antibiotic usage and duration, hospitalization period were recorded from written and electronic medical records. Mean TOA diameter had been measured in two dimensions.

All operation had been performed under general anesthesia. Patients were compared between two groups in which salpingectomy/ salpingo-oophorectomy and only abscess drainage was applied in operation. The decision about the surgical technique changed upon the fertility desire of the patient or insufficient exploration during operation due to adhesions. Only 2 patients had undergone total abdominal hysterectomy and bilateral salpingo-oophorectomy, so these 2 patients were excluded from our study. The size of TOA and the physical characteristics of the patients had determined the incision types. Median incision had been chosen in obese patients with the bigger TOA.

Our study was conducted according to the Helsinki Declaration. There was not ethical approval because we collected data of the patients from the records in archive and we did not document any personal information. Also in our hospital, informed consent is taken from every patient about that medical information may be used in scientific publications.

\section{Statistical Analysis}

Statistical analysis was performed with the Statistical Package for the Social Sciences (SPSS Inc; Chicago, IL, USA) statistics 22.0 version for Windows. Difference in mean values and characteristics between groups were analyzed with independent samples $t$ test and chi-square test. Means were presented with standard deviation (SD). $\mathrm{p}<.05$ was considered statistically significant.

\section{Results}

The mean age of the patients was $39.4 \pm 7.9$ years. Most of the patients were multiparous (98\%), gave birth normally (88.2\%), had no chronic illness $(92.2 \%)$. The mean diameter of the TOA was $6.45 \pm 1.77 \mathrm{~cm}$. The mean CA125 level was 94.9 $\pm 134.6 \mathrm{U} / \mathrm{ml}$, CRP level was $163.4 \pm 124.3$, WBC count was $14800 \pm 5700$ cells $/ \mu \mathrm{L}$. All patients had taken antibiotherapy during $13.04 \pm 4.54$ days in mean. Most of the patients had been operated with pfannenstiel incision (56.9\%). The mean hospitalization period for all patients was $11.63 \pm 4.19$ days. The complications in postoperative period was observed only in $11.8 \%$ of cases (Table 1 ).

When patients were divided into 2 groups which were operated as salpingectomy/salpingo-oophorectomy and drainage, any difference in mean values between 2 groups was not observed except WBC count (Table 2). Salpingectomy/ 
salpingo-oophorectomy had been done in $74.5 \%$ of cases and only drainage had been applied in $25.5 \%$ of cases. Total abdominal hysterectomy and bilateral salpingo-oophorectomy had been applied in only 2 patients, so this operation technique was excluded from statistical analysis. There was not any difference in characteristics between these two groups except the presence of IUD (Table 3).

When the characteristics and mean values of patients were also compared according to different incision types, any difference was not found (Table 4).

Table 1: Demographic characteristics

\begin{tabular}{|c|c|c|}
\hline Characteristics & $\begin{array}{c}\text { Number } \\
(n)\end{array}$ & $\begin{array}{c}\text { Percentage } \\
(\%)\end{array}$ \\
\hline \multicolumn{3}{|l|}{ Parity } \\
\hline Nulliparous & 1 & 2 \\
\hline Multiparous & 50 & 98 \\
\hline \multicolumn{3}{|l|}{ Vaginal birth } \\
\hline Zero & 6 & 11.8 \\
\hline$\geq 1$ & 45 & 88.2 \\
\hline \multicolumn{3}{|l|}{ Cesarean section } \\
\hline Zero & 43 & 84,3 \\
\hline$\geq 1$ & 8 & 15,7 \\
\hline \multicolumn{3}{|l|}{ Intrauterine devices } \\
\hline Absence & 39 & 76.5 \\
\hline Presence & 12 & 23.5 \\
\hline \multicolumn{3}{|l|}{ Chronic illness } \\
\hline Absence & 47 & 92.2 \\
\hline Presence & 4 & 7.8 \\
\hline \multicolumn{3}{|l|}{ Operation history } \\
\hline Absence & 43 & 84.3 \\
\hline Presence & 8 & 15.7 \\
\hline \multicolumn{3}{|l|}{ Incision type } \\
\hline Pfannenstiel & 29 & 56.9 \\
\hline Median & 13 & 25.5 \\
\hline Laparoscopy & 9 & 17.6 \\
\hline \multicolumn{3}{|l|}{ Operation } \\
\hline Salpingectomy/ salpingo-oophorectomy & 38 & 74.5 \\
\hline Drainage & 13 & 25.5 \\
\hline \multicolumn{3}{|l|}{ Complication } \\
\hline Absence & 45 & 88.2 \\
\hline Presence & 6 & 11.8 \\
\hline
\end{tabular}

Table 2: Difference in mean values of characteristics between Group 1 and 2

\begin{tabular}{lccc}
\hline Characteristics & $\begin{array}{c}\text { Group 1 } \\
(\mathrm{n}: 38)\end{array}$ & $\begin{array}{c}\text { Group 2 } \\
(\mathrm{n}: 13)\end{array}$ & $p$ \\
\hline Age & $39.13 \pm 7.08$ & $40.23 \pm 10.26$ & .131 \\
Parity $(\mathrm{no})$ & $2.4 \pm 1.3$ & $2.1 \pm 1.1$ & .283 \\
Size $(\mathrm{cm})$ & $6.4 \pm 1.8$ & $6.5 \pm 1.9$ & .713 \\
CA125 $(\mathrm{U} / \mathrm{mL})$ & $107.8 \pm 148.7$ & $45.8 \pm 24.6$ & .123 \\
CRP & $165.4 \pm 127.4$ & $157.7 \pm 119.7$ & .880 \\
WBC $\left(10^{3}\right.$ cells/ $\left.\mu \mathrm{L}\right)$ & $14.7 \pm 6.4$ & $15.3 \pm 3.4$ & .044 \\
Antibiotherapy duration (days) & $12.5 \pm 4.6$ & $14.3 \pm 4.2$ & .229 \\
Hospitalization (days) & $11.7 \pm 4.5$ & $11.3 \pm 3.4$ & .345 \\
\hline
\end{tabular}


Table 3: Distribution of characteristics

\begin{tabular}{|c|c|c|c|}
\hline Characteristics & $\begin{array}{l}\text { Group } 1 \\
(n: 38)\end{array}$ & $\begin{array}{l}\text { Group } 2 \\
(n: 13)\end{array}$ & $\mathrm{p}$ \\
\hline \multicolumn{4}{|l|}{ Parity } \\
\hline Nulliparous & $1(100 \%)$ & $0(0 \%)$ & .555 \\
\hline Multiparous & $37(74 \%)$ & $13(26 \%)$ & \\
\hline \multicolumn{4}{|l|}{ Vaginal birth } \\
\hline Zero & $4(66.7 \%)$ & $2(33.3 \%)$ & .639 \\
\hline$\geq 1$ & $34(75.6 \%)$ & $11(24.4 \%)$ & \\
\hline \multicolumn{4}{|l|}{ Cesarean section } \\
\hline Zero & $32(74.4 \%)$ & $11(25.6 \%)$ & .972 \\
\hline$\geq 1$ & $6(75 \%)$ & $2(25 \%)$ & \\
\hline \multicolumn{4}{|c|}{ Intrauterine devices } \\
\hline Absence & $32(82.1 \%)$ & $7(17.9 \%)$ & .026 \\
\hline Presence & $6(50 \%)$ & $6(50 \%)$ & \\
\hline \multicolumn{4}{|l|}{ Chronic illness } \\
\hline Absence & $35(74.5 \%)$ & $12(25.5 \%)$ & .981 \\
\hline Presence & $3(75 \%)$ & $1(25 \%)$ & \\
\hline \multicolumn{4}{|l|}{ Operation history } \\
\hline Absence & $33(76.7 \%)$ & $10(23.3 \%)$ & .396 \\
\hline Presence & $5(62.5 \%)$ & $3(37.5 \%)$ & \\
\hline \multicolumn{4}{|l|}{ Incision type } \\
\hline Pfannenstiel & $23(79.3 \%)$ & $6(20.7 \%)$ & .069 \\
\hline Median & $11(84.6 \%)$ & $2(15.4 \%)$ & \\
\hline Laparoscopy & $4(44.4 \%)$ & $5(55.6 \%)$ & \\
\hline \multicolumn{4}{|l|}{ Complication } \\
\hline Absence & $33(73.3 \%)$ & $12(26.7 \%)$ & .598 \\
\hline Presence & $5(83.3 \%)$ & $1(16.7 \%)$ & \\
\hline
\end{tabular}

Table 4: Difference in characteristics of patients according to incision type

\begin{tabular}{|c|c|c|c|c|}
\hline & Pfannenstiel (n:29) & Median (n:13) & Laparoscopy (n:9) & $\mathrm{p}$ \\
\hline \multicolumn{5}{|l|}{ Operation history } \\
\hline Absence & $25(58.1 \%)$ & $11(25.6 \%)$ & $7(16.3 \%)$ & .831 \\
\hline Presence & $4(50 \%)$ & $2(25 \%)$ & $2(25 \%)$ & \\
\hline \multicolumn{5}{|l|}{ Operation } \\
\hline Salpingectomy/ salpingo-oophorectomy & $23(60.5 \%)$ & $11(28.9 \%)$ & $4(10.5 \%)$ & .069 \\
\hline Drainage & $6(46.2 \%)$ & $2(15.4 \%)$ & $5(38.5 \%)$ & \\
\hline \multicolumn{5}{|l|}{ Complication } \\
\hline Absence & $26(57.8 \%)$ & $10(22.2 \%)$ & $9(20 \%)$ & .239 \\
\hline Presence & $3(50 \%)$ & $3(50 \%)$ & $0(0 \%)$ & \\
\hline Mean TOA size $(\mathrm{cm})$ & $6.2 \pm 1.8$ & $7.0 \pm 1.8$ & $6.4 \pm 1.7$ & .906 \\
\hline Mean hospitalization (days) & $11.3 \pm 4.2$ & $13.4 \pm 3.9$ & $10.1 \pm 3.9$ & .888 \\
\hline Mean antibiotherapy duration (days) & $13.4 \pm 4.7$ & $12.4 \pm 5.3$ & $12.7 \pm 2.9$ & .161 \\
\hline
\end{tabular}

\section{Discussion}

The decision about hospitalization of the patient with PID or TOA and operation of this patient is critical because of the sequela of this condition. Approximately $25 \%$ of these patients experience long-term sequela (12). TOA especially large ones necessitate surgical processes (13).
Laparoscopy or laparotomy is necessary for both definitive diagnosis and treatment of TOA. Surgical exploration with removal of the involved tube and ovary and drainage of purulent fluid accumulated in pelvis is lifesaving (8).

Broad spectrum parenteral antibiotherapy decrease need for surgery for treatment of TOA (14). If relief of pain or im- 
provement of symptoms does not occur, surgery is unavoidable. Larger size of abscess and older age of patients are associated with increased duration of hospitalization and increased need for surgery $(4,9)$. Radiographic size and parity are also important for surgical intervention (15). Combination of conservative surgical procedures such as intravenous antibiotherapy and unilateral salpingo-oophorectomy reduces more radical surgery such as total abdominal hysterectomy and bilateral salpingo-oophorectomy or repair of bowel injury. Percutaneous drainage guided with imaging methods and laparoscopic treatment of TOA are popular treatment options (5). The surgical approach can change according to the skill of the surgeon. Surgeries for TOA can result in severe complications because of the extensive adhesions to the surrounding organs.

We did not identify any statistically significant difference between patients who had been applied salpingectomy/ salpingo-oophorectomy and only abscess drainage in our study. It is thought that with widespread use of the effective antibiotic treatment, surgical management has become much more conservative for protection of the ovarian reserve. Higher WBC count in Group 2 could be explained as that more inflammatory response developed depending on the diffuse content of the ruptured TOA in pelvis and only drainage could be applied because of the extensive adhesions.

Absence of IUD was found in Group 1 more commonly. The explanation for this condition was that if there was not IUD, TOA became more intact and localized, so salpingectomy/salpingo-oophorectomy could be applied easier by the surgeon.

Our study has a major limitation. The follow-up of the patients in the postoperative period cannot be done, so we do not know the recurrence rate after different surgical techniques.

It is important to emphasize that early suspicion of TOA is significant for diagnosis. Treatment must be a combination of parenteral antibiotics and early surgical procedure (16). There is not any difference between different surgical techniques. But additionally more studies with more patients are needed to better understand which operation technique is more effective and less complicated.

\section{References}

1. Chappell CA, Wiesenfeld HC. Pathogenesis, diagnosis and management of severe pelvic inflammatory disease and tuboovarian abscess. Clin Obstet Gynecol 2012;55 (4):893-903.

2. Schorge JO, Schaffer JI, Halvorson LM, Hoffman B, Bradshaw KD, Cunnıngham FG. Gynecologic Infections: In Williams Gynecology. 1st edition. McGraw-Hill 2009: 49-85.
3. Hajj SN, Mercer LJ, Ismail MA. Surgical approaches to pelvic infections in women. J Reprod Med 1988;33 (1 Suppl):159-63.

4. DeWitt J, Reining A, Allsworth JE, Peipert JF. Tuboovarian abscesses: Is size associated with duration of hospitalization and complications? Obstet Gynecol Int.; 2010: 847041, doi:10.1155/2010/847041. Epub 2010 May 24.

5. Wiesenfeld HC, Sweet RL. Progress in the management of tuboovarian abscesses. Clin Obstet Gynecol 1993;36(2): 433-44.

6. Burkman RT. Intrauterine devices and pelvic inflammatory disease: evolving perspectives on the data. Obstet Gynecol Surv 1996;51(12 Suppl):S35-41.

7. Landers DV, Sweet RL. Current trends in the diagnosis and treatment of tuboovarian abscess. Am J Obstet Gynecol 1985;151(8):1098-110.

8. Soper DE. Pelvic inflammatory disease. Obstet Gynecol 2010;116(2 Pt 1):419-28.

9. Halperin R, Svirsky R, Vaknin Z, Ben-Ami I, Schneider D, Pansky M. Predictors of tuboovarian abscess in acute pelvic inflammatory disease. J Reprod Med 2008;53(1): 40-4.

10. Mercer LJ, Hajj SN, Ismail MA, Block BS. Use of C-reactive protein to predict the outcome of medical management of tuboovarian abscesses. J Reprod Med 1988;33(1 Suppl):164-7.

11. Gjelland K, Ekerhovd E, Granberg S. Transvaginal ultrasound-guided aspiration for treatment of tubo-ovarian abscess: a study of 302 cases. Am J Obstet Gynecol 2005; 193(4):1323-30.

12. Hurt KJ, Duile MW, Bienstock JL, Fox HE, Wallach EE. Infections of the genital tract. In: The Johns Hopkins Manual of Gynecology and Obstetrics. $4^{\text {th }}$ edition 2011: $322-40$.

13. Reed SD, Landers DV, Sweet RL. Antibiotic treatment of tuboovarian abscess: comparison of broad-spectrum betalactam agents versus clindamycin-containing regimens. Am J Obstet Gynecol 1991;164(6 Pt 1):1556-61.

14. Yasa C, Dural O, Bastu E, Yumru H, Demir O, Uğurlucan FG. Evaluation of the Results of Conservative Management of Women with Tuboovarian Abscess; Single Tertiary Center Experience. Gynecol Obstet Reprod Med 2016;22(2):90-3.

15. Greenstein Y, Shah AJ, Vragovic O, Cabral H, SotoWright V, Borgatta L, et al. Tuboovarian abscess. Factors associated with operative intervention after failed antibiotic therapy. J Reprod Med 2013;58(3-4):101-6.

16. Reich H, McGlynn F. Laparoscopic treatment of tuboovarian and pelvic abscess. J Reprod Med 1987;32 (10):747-52. 